\title{
Research on the Performance Evaluation Model of Higher Education Teachers Based on the Improved Grey Clustering Analysis Method
}

\author{
http://dx.doi.org/10.3991/ijet.v10i8.5220 \\ Wenlu Li, Yinghui Wang \\ Shijiazhuang Tiedao University, Shijiazhuang, China
}

\begin{abstract}
Effective performance evaluation of university teachers is supposed to guide teaching behaviors and teaching modes as well as improve teaching quality of higher education. In response to the complexity of performance evaluation of university teachers, this thesis proposes a performance evaluation model based on the improved grey clustering analysis method. Firstly, an index model for evaluating performance of university teachers is established with confirmed layers and index sets. Secondly, performance evaluation grades are given out and whitenization weight functions of grey clustering under different performance grades are established. Based on the standardization of index model, and taking weight into consideration, this thesis provides an improved grey clustering analysis method for performance evaluation of university teachers. Last but not the least, the model is verified through case study to prove its efficacy and availability, which lays a sound support for improving higher education.
\end{abstract}

Index Terms-Higher education; University teachers; Performance evaluation; Grey clustering analysis method; Promotion of education ability; Model and algorithm

\section{INTRODUCTION}

Teachers, as a crucial part in higher education, play an important role in advancing teaching modes and the capability of higher education [3-4]. Therefore, the significance of establishing a system and model for evaluating performance of university teachers cannot be overlooked. Experts and scholars have discussed and analyzed such issue from different perspectives and acquired fruitful results [5-8]. Schools of higher education serve as a cradle for talent training. They are essential in disseminating, imparting and innovating knowledge useful for social and scientific development. Universities, as a result, are faced with the demand of adapting to social and scientific development [1-2].

However, the performance evaluation of university teachers is complicated system engineering. Current study is still far from enough. For example, the existing evaluation system draws much attention on parts rather than a comprehensive analysis; the evaluation target is sometimes mistaken and becomes distant from the purpose of improving education ability; the evaluation process is unclear, failing to deal with fuzzy information or resulting in improper integration of qualitative and quantitative evaluation. Therefore, this paper draws merits from previous studies with the intention of improving education ability, and proposes an improved grey clustering analysis method [11-13] for evaluating performance of university teachers, so as to provide guidance and support for improving teaching modes in higher education.

\section{PERFORMANCE EVALUATION MODEL OF UNIVERSITY TEACHERS}

Under the principle of being scientific, comprehensive, objective, practical and adaptive, this thesis studies carefully the teaching ability, research ability, social service, talent training and ethics and moral development, all of which are primary indexes. Secondary indexes are formed after each primary index is detailed. Table 1 shows the performance evaluation model of university teachers.

TABLE I. TYPE SIZES FOR CAMERA-READY PAPERS

\begin{tabular}{|c|c|c|}
\hline $\begin{array}{l}\text { Performance } \\
\text { index system }\end{array}$ & $\begin{array}{l}\text { Primary } \\
\text { index }\end{array}$ & Secondary index \\
\hline \multirow{24}{*}{$\begin{array}{l}\text { Performance } \\
\text { evaluation } \\
\text { model of } \\
\text { university } \\
\text { teachers } S\end{array}$} & \multirow{6}{*}{$\begin{array}{l}\text { Teaching } \\
\text { ability } S_{1}\end{array}$} & Innovation $s_{11}$ \\
\hline & & Efficiency $S_{12}$ \\
\hline & & Methodology $S_{13}$ \\
\hline & & Results $S_{14}$ \\
\hline & & Method $S_{15}$ \\
\hline & & Altitude $S_{16}$ \\
\hline & \multirow{6}{*}{$\begin{array}{l}\text { Research } \\
\text { ability } S_{2}\end{array}$} & Number of research projects $S_{21}$ \\
\hline & & Proportion of advanced projects $\boldsymbol{S}_{22}$ \\
\hline & & Number of articles published $\boldsymbol{S}_{23}$ \\
\hline & & Proportion of advanced articles $S_{24}$ \\
\hline & & $\begin{array}{l}\text { Integration of industry-academia-research } \\
S_{25}\end{array}$ \\
\hline & & Transformation of research results $\boldsymbol{S}_{26}$ \\
\hline & \multirow{5}{*}{$\begin{array}{l}\text { Social } \\
\text { service } S_{3}\end{array}$} & Student satisfaction $S_{31}$ \\
\hline & & School satisfaction $S_{32}$ \\
\hline & & Social contribution $\boldsymbol{S}_{33}$ \\
\hline & & Campus contribution $S_{34}$ \\
\hline & & Committee and Broad Memberships $\boldsymbol{s}_{35}$ \\
\hline & \multirow{4}{*}{$\begin{array}{l}\text { Talent } \\
\text { training } \\
S_{4}\end{array}$} & Number of students being trained $S_{41}$ \\
\hline & & Yield $s_{42}$ \\
\hline & & Echelon building of talents $S_{43}$ \\
\hline & & Social practice of student $\boldsymbol{S}_{44}$ \\
\hline & \multirow{3}{*}{$\begin{array}{l}\text { Ethics and } \\
\text { moral devel- } \\
\text { opment } S_{5}\end{array}$} & Vocational morality $s_{51}$ \\
\hline & & Academic morality $S_{52}$ \\
\hline & & Professional skill $\boldsymbol{s}_{53}$ \\
\hline
\end{tabular}


According to the performance index system, the index sets can be constructed, in which ${ }^{S^{I}}$ refers to:

$S^{I}=\left\{S_{1}^{I I}, S_{2}^{I I}, S_{3}^{I I}, S_{4}^{I I}, S_{5}^{I I}\right\}$

The secondary index set $S^{I I}$ refers to:

$\left\{\begin{array}{l}S_{1}^{I I}=\left\{s_{11}, s_{12}, s_{13}, s_{14}, s_{15}, s_{16}\right\} \\ S_{2}^{I I}=\left\{s_{21}, s_{22}, s_{23}, s_{24}, s_{25}, s_{26}\right\} \\ S_{3}^{I I}=\left\{s_{31}, s_{32}, s_{33}, s_{34}, s_{35}\right\} \\ S_{4}^{I I}=\left\{s_{41}, s_{42}, s_{43}, s_{44}\right\} \\ S_{5}^{I I}=\left\{s_{51}, s_{52}, s_{53}\right\}\end{array}\right.$

III. PERFORMANCE EVAlUATION PERFORMANCE EVALUATION MODEL OF HIGHER EDUCATION TEACHERS BASED ON THE IMPROVED GREY CLUSTERING ANALYSIS METHOD MODEL OF UNIVERSITY TEACHERS

\section{A. Improved whitenization weight function}

The whitenization weight function is a key link of grey clustering analysis. To make sure that the whitenization weight shares the same membership degree with the performance evaluation grade, we have to satisfy the premises that the whitenization weight function is a constant function changing with independent variable and that the whitenization weight functions of every two grades that are no adjacent to each other do not have intersections. And each whitenization weight function has the quantity value of 1 and on each side of the quantity value the function is monotonous. The improved whitenization weight function is constructed in Fig.1.

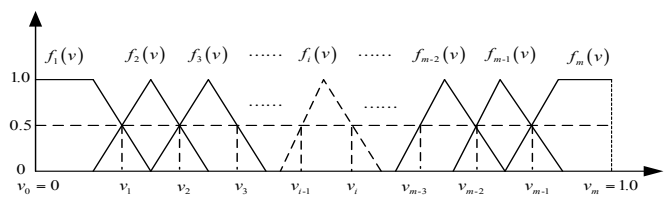

Figure 1.

According to Fig.1, the corresponding whitenization weight function model can be constructed as:

$$
\begin{aligned}
& \int 0 \quad v \in\left[\frac{v_{2}+v_{1}}{2}, 1\right] \\
& f_{1}(v)= \begin{cases}\frac{v_{2}+v_{1}-2 v}{2\left(v_{2}-v_{1}\right)} & v \in\left[v_{1}, \frac{v_{2}+v_{1}}{2}\right] \\
\frac{3 v_{1}-2 v}{2 v_{1}} & v \in\left[\frac{v_{1}+v_{0}}{2}, v_{1}\right] \\
1 & v \in\left[v_{0}, \frac{v_{1}+v_{0}}{2}\right]\end{cases} \\
& f_{i}(v)= \begin{cases}\frac{2 v-v_{i-1}-v_{i-2}}{2\left(v_{i-1}-v_{i-2}\right)} & v \in\left[\frac{v_{i-1}+v_{i-2}}{2}, v_{i-1}\right] \\
\frac{2 v+v_{i}-3 v_{i-1}}{2\left(v_{i}-v_{i-1}\right)} & v \in\left[v_{i-1}, \frac{v_{i}+v_{i-1}}{2}\right] \\
0 & v \in\left[v_{0}, \frac{v_{i-2}+v_{i-1}}{2}\right] \cup\left[\frac{v_{i}+v_{i+1}}{2}, 1\right] \\
\frac{3 v_{i}-v_{i-1}-2 v}{2\left(v_{i}-v_{i-1}\right)} & v \in\left[\frac{v_{i}+v_{i-1}}{2}, v_{i}\right] \\
\frac{v_{i}+v_{i+1}-2 v}{2\left(v_{i+1}-v_{i}\right)} & v \in\left[v_{i}, \frac{v_{i}+v_{i+1}}{2}\right]\end{cases}
\end{aligned}
$$

where there is $2 \leq i \leq(m-1)$.

$$
f_{m}(v)= \begin{cases}1 & v \in\left[\frac{v_{m-1}+1}{2}, 1\right] \\ \frac{2 v+1-3 v_{m-1}}{2\left(v_{m}-v_{m-1}\right)} & v \in\left[v_{m-1} \frac{v_{m-1}+v_{m}}{2}\right] \\ \frac{2 v-v_{m-1}-v_{m-2}}{2\left(v_{m-1}-v_{m-2}\right)} & v \in\left[\frac{v_{m-1}+v_{m-2}}{2}, v_{m-1}\right] \\ 0 & v \in\left[v_{0}, \frac{v_{m-1}+v_{m-2}}{2}\right]\end{cases}
$$

\section{B. Establishing performance evaluation grade}

To effectively evaluate the grade of the subject, this thesis adopts a five-grade evaluation mechanism after consulting experts, scholars and leaders in the education sector while abiding by relevant systems and standards.

The five grades are excellent $\boldsymbol{g}_{\text {exc }}$, good $\boldsymbol{g}_{\text {goo }}$, mediocre $\boldsymbol{g}_{\text {med }}$, general $\boldsymbol{g}_{\text {gen }}$ and poor $\boldsymbol{g}_{\text {poo }}$.

In order to achieve the same membership scale of evaluation subjects, this thesis adopts a $0-1$ grade to divide the performance evaluation interval. The excellent grade is $0.9-1.0$, followed by the good grade, which takes up 0.80.9 . Next is the mediocre grade, taking up $0.7-0.8$, followed by the general grade, which takes up 0.6-0.7. And the last is the poor, taking up $0-0.6$. So, the grade set $G$ of performance evaluation of university teachers is expressed as:

$$
\begin{aligned}
& G= \\
& \left\{g_{\text {oec }}\left|(0.9-1.0), g_{\text {goo }}\right|(0.8-0.9), g_{\text {med }}\left|(0.7-0.8), g_{\text {gen }}\right|(0.6-0.7), g_{\text {poo }} \mid(0-0.6)\right\}
\end{aligned}
$$

\section{Standardization of evaluation index}

From the evaluation system, it can be seen that performance evaluation grades for different teachers are presented in different forms. Some are qualitative description and others are quantitative description. There are positive indexes, negative indexes and moderate indexes. Thus, we need to standardize these indexes to evaluate based on unified grade.

Qualitative indexes usually have fuzzy qualitative description. The fuzzy language needs to go through quantitative transformation according to grade of qualitative description. The finer the grade, the more definite the quantitative value is after transformation. This thesis adopts 0-1 scale to conduct quantitative transformation on qualitative indexes. 1 refers to excellent qualitative description and 0 refers to poor qualitative description. Other quantitative values are confirmed based on fuzzy description.

For positive quantitative index $j$, if the initial value is $v_{j}$, the maximum threshold of its corresponding index is $v_{j}^{\max }$ while the minimum is $v_{j}^{\min }$, so the quantitative value $\boldsymbol{u}_{j}$ after standardization is:

$$
u_{j}=\frac{v_{j}-v_{j}^{\min }}{v_{j}^{\max }-v_{j}^{\min }}
$$


For negative quantitative index $j$, if the initial value is

$v_{j}$, the maximum threshold of its corresponding index is $v_{j}^{\max }$ while the minimum is $v_{j}^{\min }$, so the quantitative value $\boldsymbol{u}_{j}$ after standardization is:

$$
u_{j}=\frac{v_{j}^{\max }-v_{j}}{v_{j}^{\max }-v_{j}^{\min }}
$$

For moderate quantitative index $j$, if the initial value is $\mathcal{V}_{j}$, the maximum threshold of its corresponding index is $v_{j}^{\max }$ while the minimum is $v_{j}^{\min }$, so the quantitative value $\boldsymbol{u}_{j}$ after standardization is:

$$
u_{j}=1-\frac{\left|v_{j}-\left(v_{j}^{\max }+v_{j}^{\min }\right) / 2\right|}{\left|\left(v_{j}^{\max }-v_{j}^{\min }\right) / 2\right|}
$$

\section{Establishing the performance evaluation model}

Based on the grades of performance evaluation of university teachers, we can work out the whitenization weight function of five grades, namely $f_{g_{p o o}}(v)$, $f_{g_{\text {gen }}}(v) \quad f_{g_{\text {med }}}(v) \quad f_{g_{\text {goo }}}(v)$ and $f_{\text {gexc }}(v)$. There is $v_{0}=0, v_{1}=0.6 v_{2}=0.7$ $v_{3}=0.8 v_{4}=0.9$ and $v_{5}=1.0$.

The whitenization weight function $\mathcal{f}_{g_{\text {poo }}}(\nu)$ corresponding to the poor grade $\boldsymbol{g}_{\text {poo is: }}$

$$
f_{g_{p o o}}(v)= \begin{cases}0 & v \in[0.65,1] \\ \frac{1.3-2 v}{0.2} & v \in[0.6,0.65] \\ \frac{1.8-2 v}{1.2} & v \in[0.3,0.6] \\ 1 & v \in[0,0.3]\end{cases}
$$

The whitenization weight function $\mathscr{f}_{g_{\text {gen }}}(\nu)$ corresponding to the general grade $\mathcal{S}_{\text {gen }}$ is:

$$
f_{g_{g e n}}(v)= \begin{cases}\frac{2 v-0.6}{1.2} & v \in[0.3,0.6] \\ \frac{2 v-1.1}{0.2} & v \in[0.6,0.65] \\ 0 & v \in[0,0.3] \cup[0.75,1] \\ \frac{1.5-2 v}{0.2} & v \in[0.65,0.75]\end{cases}
$$

The whitenization weight function $\boldsymbol{f}_{\boldsymbol{g}_{\text {med }}}(\boldsymbol{v})$ corresponding to the moderate grade $\boldsymbol{S}_{\text {med }}$ is:

$$
f_{g_{\text {med }}}(v)=\left\{\begin{array}{lc}
\frac{2 v-1.3}{1.2} & v \in[0.65,0.75] \\
0 & v \in[0,0.65] \cup[0.85,1] \\
\frac{1.7-2 v}{0.2} & v \in[0.75,0.85]
\end{array}\right.
$$

The whitenization weight function $\mathcal{F}_{g_{g o o}}(\nu)$ corresponding to the good grade $\boldsymbol{g}_{\text {goo }}$ is:

$$
f_{g_{g o o}}(v)=\left\{\begin{array}{lrl}
\frac{2 v-1.5}{1.2} & v \in[0.75,0.85] \\
0 & v \in[0,0.75] \cup[0.95,1] \\
\frac{1.9-2 v}{0.2} & v \in[0.85,0.95]
\end{array}\right.
$$

The whitenization weight function $\mathcal{f}_{g_{\text {exc }}}(\nu)$ corresponding to the excellent grade $\boldsymbol{g}_{\text {exc }}$ is:

$$
f_{g_{\text {exc }}}(v)= \begin{cases}1 & v \in[0.95,1] \\ \frac{2 v-1.7}{0.2} & v \in[0.85,0.95] \\ 0 & v \in[0,0.85]\end{cases}
$$

In the model, with the weight of index $k$ in the secondary set $S^{I I}$ to be obtained, the grey clustering coefficient of whitening weight function $\mathcal{f}_{g_{1}}(v)$ corresponding to index $k$ under different performance evaluation grades is calculated as $\delta_{k l}^{I I}=f_{g_{l}}\left(v_{\mathrm{k}}\right)$. Based on the weight $w_{k}^{I I}$ of index $\boldsymbol{k}$ in the secondary index set ${ }^{S^{I I}}$, the comprehensive clustering coefficient $\delta_{l}^{I}$ is calculated as:

$$
\delta_{l}^{I}=\sum_{\mathrm{k}=1}^{n_{k}}\left(w_{k}^{I I} * \delta_{k l}^{I I}\right)=\sum_{\mathrm{k}=1}^{n_{k}}\left(w_{k}^{I I} * f_{g_{l}}\left(v_{\mathrm{k}}\right)\right)
$$

If the weight of index $q$ in the primary set is ${ }^{w_{q}^{I}}$, the comprehensive clustering coefficient $\delta_{l}^{I}$ of all index $\mathrm{q}$ under different performance evaluation grades is:

$$
\delta_{l}=\sum_{q=1}^{n_{q}}\left(w_{q}^{I} * \delta_{l}^{I}\right)=\sum_{q=1}^{n_{q}}\left(w_{q}^{I} * \sum_{k=1}^{n_{k}}\left(w_{k}^{I I} * \delta_{k l}^{I I}\right)\right)
$$

The bigger the comprehensive grey clustering coefficient $\delta_{l}$ is, the closer the grade of the evaluated teacher to grade $l$ and vice versa. So, comprehensive grey clustering coefficient $\delta_{l}$ enables us to figure out in which grade the subject falls.

\section{E. Realization of performance evaluation algorithm}

As is discussed above, the performance evaluation model of higher education teachers based on the improved grey clustering analysis method is exercised as below:

Step1 Construct the performance evaluation model of university teachers and obtain the primary index set and the secondary index set according to Equ. (1) and (2).

Step2 Obtain the improved grey weight function model according to Equ. (3)- (5).

Step 3 Construct the grade of performance evaluation of university teachers according to Equ. (6).

Step 4 Standardize qualitative indexes and quantitative indexes according to Equ. (7)-(9) and description in Section 3.3 to unify the standard.

Step 5 Construct the whitening weight function model of performance evaluation according to Equ. (10)- (15). 
Step 6 Obtain the comprehensive grey clustering coefficient of subjects under different performance evaluation grades according to Equ. (16)- (17).

Step 7 Obtain the grade of the subject based on the comprehensive grey clustering coefficient.

\section{CASE STUDY AND ANALYSIS}

This thesis explains the model and the algorithm with the study of the performance evaluation of teachers in a university. The performance of a teacher is confirmed through the combination of several ways including expert scoring, questionnaire and statistics. These data are standardized as required, and the result of which is shown in Table II.

Therefore, the sequence of comprehensive grey clustering coefficient of this teacher is $\boldsymbol{\delta}=(0.375,0.344,0.175,0.051,0.052)$, from which we can see the teacher is in the excellent grade.

Thus, construct the whitening weight function model of performance evaluation of teachers and obtain the grey clustering coefficient, as shown in Table III and IV.

TABLE II.

PERFORMANCE EVALUATION OF TEACHERS

\begin{tabular}{|c|c|c|c|c|c|c|}
\hline $\begin{array}{c}\text { Pri- } \\
\text { mary } \\
\text { index }\end{array}$ & Weight & $\begin{array}{c}\text { Second- } \\
\text { ary index }\end{array}$ & Weight & $\begin{array}{c}\text { Prelimi- } \\
\text { nary data }\end{array}$ & $\begin{array}{l}\text { Standard- } \\
\text { ized data }\end{array}$ & $\begin{array}{l}\text { Type of } \\
\text { index }\end{array}$ \\
\hline \multirow{6}{*}{$S_{1}$} & \multirow{6}{*}{0.30} & $s_{11}$ & 0.15 & 0.90 & 0.90 & qualitative \\
\hline & & $s_{12}$ & 0.25 & 0.85 & 0.85 & qualitative \\
\hline & & $s_{13}$ & 0.15 & 0.90 & 0.90 & qualitative \\
\hline & & $s_{14}$ & 0.20 & 0.80 & 0.80 & qualitative \\
\hline & & $s_{15}$ & 0.10 & 0.95 & 0.95 & qualitative \\
\hline & & $s_{16}$ & 0.15 & 0.95 & 0.95 & qualitative \\
\hline \multirow{6}{*}{$S_{2}$} & \multirow{6}{*}{0.20} & $s_{21}$ & 0.10 & 2.5 & 0.80 & quantitative \\
\hline & & $s_{22}$ & 0.20 & 0.80 & 0.80 & quantitative \\
\hline & & $s_{23}$ & 0.10 & 8 & 0.80 & quantitative \\
\hline & & $s_{24}$ & 0.20 & 0.75 & 0.75 & quantitative \\
\hline & & $s_{25}$ & 0.20 & 0.65 & 0.65 & qualitative \\
\hline & & $s_{26}$ & 0.20 & 0.35 & 0.35 & quantitative \\
\hline \multirow{5}{*}{$S_{3}$} & \multirow{5}{*}{0.15} & $s_{31}$ & 0.20 & 0.95 & 0.95 & qualitative \\
\hline & & $s_{32}$ & 0.20 & 0.90 & 0.90 & quantitative \\
\hline & & $s_{33}$ & 0.25 & 0.80 & 0.80 & qualitative \\
\hline & & $s_{34}$ & 0.20 & 0.85 & 0.85 & qualitative \\
\hline & & $s_{35}$ & 0.15 & 0.50 & 0.50 & qualitative \\
\hline \multirow{4}{*}{$S_{4}$} & \multirow{4}{*}{0.20} & $s_{41}$ & 0.15 & 125 & 0.83 & quantitative \\
\hline & & $S_{42}$ & 0.30 & 0.98 & 0.98 & quantitative \\
\hline & & $s_{43}$ & 0.35 & 0.85 & 0.85 & qualitative \\
\hline & & $S_{44}$ & 0.20 & 0.75 & 0.75 & qualitative \\
\hline \multirow{3}{*}{$S_{5}$} & \multirow{3}{*}{0.15} & $s_{51}$ & 0.30 & 0.95 & 0.95 & qualitative \\
\hline & & $s_{52}$ & 0.30 & 0.95 & 0.95 & qualitative \\
\hline & & $s_{53}$ & 0.40 & 0.95 & 0.95 & qualitative \\
\hline
\end{tabular}

TABLE III. GREY CLUSTERING COEFFICIENT OF SECONDARY INDEX

\begin{tabular}{|c|c|c|c|c|c|}
\hline \multirow{2}{*}{$\begin{array}{l}\text { Secondary } \\
\text { index }\end{array}$} & \multicolumn{5}{|c|}{ Evaluation grade } \\
\hline & $g_{\text {exc }}$ & $g_{g o o}$ & $g_{\text {med }}$ & $g_{\text {gen }}$ & $g_{\text {poo }}$ \\
\hline$S_{11}$ & 0.500 & 0.500 & 0 & 0 & 0 \\
\hline$s_{12}$ & 0 & 1.000 & 0 & 0 & 0 \\
\hline$s_{13}$ & 0.500 & 0.500 & 0 & 0 & 0 \\
\hline$s_{14}$ & 0 & 0.500 & 0.500 & 0 & 0 \\
\hline$s_{15}$ & 1.000 & 0 & 0 & 0 & 0 \\
\hline$s_{16}$ & 1.000 & 0 & 0 & 0 & 0 \\
\hline$s_{21}$ & 0 & 0.500 & 0.500 & 0 & 0 \\
\hline$s_{22}$ & 0 & 0.500 & 0.500 & 0 & 0 \\
\hline$s_{23}$ & 0 & 0.500 & 0.500 & 0 & 0 \\
\hline$s_{24}$ & 0 & 0 & 1.000 & 0 & 0 \\
\hline $\boldsymbol{s}_{25}$ & 0 & 0 & 0 & 1.000 & 0 \\
\hline$s_{26}$ & 0 & 0 & 0 & 0.083 & 0.917 \\
\hline$s_{31}$ & 1.000 & 0 & 0 & 0 & 0 \\
\hline $\boldsymbol{s}_{32}$ & 0.500 & 0.500 & 0 & 0 & 0 \\
\hline $\boldsymbol{S}_{33}$ & 0 & 0.500 & 0.500 & 0 & 0 \\
\hline$s_{34}$ & 0 & 1.000 & 0 & 0 & 0 \\
\hline $\boldsymbol{s}_{35}$ & 0 & 0 & 0 & 0.333 & 0.667 \\
\hline$s_{41}$ & 0 & 0.800 & 0.200 & 0 & 0 \\
\hline$s_{42}$ & 1.000 & 0 & 0 & 0 & 0 \\
\hline$s_{43}$ & 0 & 1.000 & 0 & 0 & 0 \\
\hline$s_{44}$ & 0 & 0 & 1.000 & 0 & 0 \\
\hline$s_{51}$ & 1.000 & 0 & 0 & 0 & 0 \\
\hline$s_{52}$ & 1.000 & 0 & 0 & 0 & 0 \\
\hline $\boldsymbol{s}_{53}$ & 1.000 & 0 & 0 & 0 & 0 \\
\hline
\end{tabular}

TABLE IV. GREY CLUSTERING COEFFICIENT OF PRIMARY INDEX

\begin{tabular}{c|c|c|c|c|c}
\hline \multirow{2}{*}{$\begin{array}{c}\text { Primary } \\
\text { index }\end{array}$} & \multicolumn{5}{|c}{ Evaluation grade } \\
\cline { 2 - 6 } & $\boldsymbol{g}_{\text {exc }}$ & $\boldsymbol{g}_{\text {goo }}$ & $\boldsymbol{g}_{\text {med }}$ & $\boldsymbol{g}_{\text {gen }}$ & $\boldsymbol{g}_{\text {poo }}$ \\
\hline$S_{1}$ & 0.120 & 0.150 & 0.030 & 0 & 0 \\
\hline$S_{2}$ & 0 & 0.040 & 0.080 & 0.043 & 0.037 \\
\hline$S_{3}$ & 0.045 & 0.064 & 0.019 & 0.008 & 0.015 \\
\hline$S_{4}$ & 0.060 & 0.094 & 0.046 & 0 & 0 \\
\hline$S_{5}$ & 0.150 & 0 & 0 & 0 & 0 \\
\hline
\end{tabular}

\section{CASE STUDY AND ANALYSIS}

To better guide teaching behaviors and teaching modes, and improve the quality of higher education, this thesis proposes a performance evaluation model of university teachers based on the improved grey clustering analysis method. By establishing the index model and improved whitenization weight function, this thesis also standardizes indexes and acquires grades of performance evaluation of teachers. The model is easy to calculate and has a clear physical significance. It provides guidance for improving teaching ability of university teachers. 


\section{REFERENCES}

[1] Li Yusong. Construction of Performance Evaluation Model of University Teachers based on KPI [J]. Theory Learning, 2011, 18: 285-286.

[2] Ding Zhenhua, Wu Yingyu. A Review of Performance Evaluation in Higher Education [J]. Journal of hunan normal university education sciences, 2010, 9 (2): 89-94.

[3] Liu Yeyun, Li Xue. Construction of the Evaluation Index System of Chinese University Teacher's Capability [J]. Jiangsu's Higher Educaiton, 2014, 4: 64-66.

[4] Guo Xiufang. Analysis on Fuzzy Comprehensive Evaluation of Teachers in Higher Education-based on AHP [J]. Modern Business Trade Industry, 2013, 6: 90-91.

[5] Zuo Heping, Li Yuqing. The Application of Fuzzy Analysis in Performance Evaluation of Higher Educadtion [J]. Education Research Monthly, 2012, 8: 63-65.

[6] Liu Quanfei. Construction of New Type Scientific Research Performance Model based on AHP [J]. Technology and Innovation Management, 2015, 36(2): 138-141.

[7] Tian Guoshuang, Shang Hangbiao, Quan Liang. Construction of Performance Evaluation System of University Teachers [J] . Heilongjiang Researches on Higher Education. 2013, 10: 91-94.

[8] Lin Hongquan, Wang Guowu. Theory and Practice of Evaluation System of University Teachers based on AHP [J]. Modern Education Technology, 2013, 23 (7): 38-42.

[9] Muhammad Saad Memon, Young Hae Lee, Sonia Irshad Mari. Group multi-criteria supplier selection using combined grey systems theory and uncertainty theory $[\mathrm{J}]$. Expert Systems with Applications, 2015, 42 (21): 7951-7959. http://dx.doi.org/10.1016/ j.eswa.2015.06.018

[10] Seyed Hamid Hashemi, Amir Karimi, Madjid Tavana. An integrated green supplier selection approach with analytic network process and improved Grey relational analysis $[\mathrm{J}]$. International
Journal of Production Economics, 2015, 159(1): 178-191. http://dx.doi.org/10.1016/j.ijpe.2014.09.027

[11] Xuemei Li, Keith W. Hipel, Yaoguo Dang. An improved grey relational analysis approach for panel data clustering [J]. Expert Systems with Applications, 2015, 42(23): 9105-9116. http://dx.doi.org/10.1016/j.eswa.2015.07.066

[12] R. Rajesh, V. Ravi. Supplier selection in resilient supply chains: a grey relational analysis approach [J]. Journal of Cleaner Production, 2015, 86(1): 343-359. http://dx.doi.org/10.1016/ j.jclepro.2014.08.054

[13] Liu Ke, Shen Xiaoliu, Tan Zhongfu, Guo Wenyan, Grey Clustering Analysis Method for Overseas Energy Project Investment Risk Decision [ J ]. Systems Engineering Procedia, 2014, 3: 55-62. http://dx.doi.org/10.1016/j.sepro.2011.11.008

\section{AUTHORS}

Wenlu Li, she received her M.Sc. in business management (2001), and PhD in management (2007) from university. Now she is full associate professor of school of economics and management, Shijiazhuang Tiedao University Shijiazhuang, 050043, China. Her current research interests include marketing management and logistics. (liwenlu0616@126.com).

Yinghui Wang, he received his M.Sc. in business management (2000), and $\mathrm{PhD}$ in Management Science and Engineering (2006) from university. Now he is full associate professor of school of economics and management, Shijiazhuang Tiedao University Shijiazhuang, 050043, China. His current research interests include institutional economics and logistics. (wang112111@163.com).

Submitted 07 November 2015. Published as resubmitted by the authors 05 December 2015. 